\title{
Diagnosis of Acute Kidney Injury: Current Controversies
}

\section{Chia Ter Chao*}

Department of Internal Medicine, National Taiwan University Hospital, Taipei, Taiwan

\section{Keywords: Acute Kidney Injury (AKI); Diagnosis; Creatinine}

Acute kidney injury (AKI) has been a global epidemic in the modern society, with amassing evidence showing that AKI occurs with increased frequency and brings about short-term/long-term complications [1-3]. AKI estimately occurs in $0.2-0.5 \%$ of communityindwelling adults per year, 5-20\% of hospitalized patients, and 30-60 of critically ill patients in different healthcare settings $[2,4,5]$. However, as we gain further knowledge with the ever-growing numbers of publications, more controversies seem to appear. In the following section, we list some of the most debated aspects in the research of AKI, especially pertaining to its diagnosis.

First, the determination of baseline serum creatinine ( $\mathrm{SCr}$ ) is one major issue. Most clinicians now recognize AKI based upon the new classification schemes, risk-injury-failure-loss-end stage (RIFLE) and acute kidney injury network (AKIN) [1-6]. Both systems place emphasis on the use of $\mathrm{SCr}$ as a diagnostic criterion, though with different threshold. Since the change of SCr requires baseline levels for calibration, the determination of patients' original renal status becomes important. However, it is common that baseline values of SCr are missing or not available [7]. Consequently, researchers devise several methods to circumvent this issue, and these corrections heretofore introduce biases. The ADQI group initially proposed a simple method, that is, to assume a baseline estimated glomerular filtration rate (GFR) of $75 \mathrm{ml} /$ $\mathrm{min} / 1.73 \mathrm{~m}^{2}$, and calculate SCr accordingly (with MDRD (Modification of Diet in Renal Disease) formula) [6]. This method is touted for its easyapplicability and convenience, since no other personal information is required. However, subsequent reports identified that such assumption potentially over-estimates the incidence of AKI, since patients with AKI more often have lower eGFR rather than "normal" level $[7,8]$. This inflation of AKI incidence might also compromise our ability to interpret any associations between AKI and subsequent events. Others propose substitution with the admission SCr values [9] or minimum SCr values during hospitalization [5,7], or choose to use the lowest outpatient values [4]. However, all these estimates potentially create errors during the diagnosis and, also, the classification and staging of AKI [8]. Recently, Siew et al. utilized multiple imputation methods, comprised of different sets of covariates, to estimate baseline GFR and SCr [7]. Using a real world validation dataset (with available baseline $\mathrm{SCr}$ ), they found that multiple imputation methods are significantly more accurate than assuming a baseline eGFR $75 \mathrm{ml} / \mathrm{min} / 1.73 \mathrm{~m}^{2}$. This method could be a promising new way for estimating a baseline $\mathrm{SCr}$ value.

The other controversial issue in the diagnosis AKI is the reliance of $\mathrm{SCr}$ on diagnosis and the discovery of next-generation biomarkers. First, SCr is notorious for its poor sensitivity in detecting renal injury $[1,6]$. The minimal time required for SCr elevation after AKI onset is 48-72 hours, and creatinine kinetics are altered in many populations, such as the elderly, the muscular male, and patients with malnutrition [10]. Common disease statuses and pathophysiologic changes could also affect the SCr values, including volume dysregulation, use of medications that interfere renal hemodynamics (like angiotensinconverting enzymes inhibitors) and sepsis [11]. This is the reason why clinicians and scientists alike are eagerly pursuing novel biomarkers for diagnosis of AKI. Currently available AKI biomarkers include plasma, serum or urine neutrophil gelatinase-associated lipocalin (NGAL), kidney injury molecule (KIM)-1, L type fatty acid binding protein (L-FABP), interleukin (IL)-18, netrin-1, and sodium hydrogen exchanger type 3 (NHE3) [12]. They all rise hours after renal insult occurs, and demonstrate prominent elevation compared with their original level. Except NGAL, which is well validated, other markers are still being actively tested for their role in diagnosing AKI. However, all these molecules are limited one way or not, and most important of all, the detection kits for these molecules are expensive and not amenable to large-scale testing. Despite these restrains and economical issues, the future of biomarkers for trailing paths of AKI is still promising. It is expected that we can someday recognize AKI in all populations earlier, and effectively interfere with its natural course so as to reduce the burden and sequels it carry.

\section{References}

1. Bellomo R, Ronco C, Kellum JA, Mehta RL, Palevsky P, et al. (2004) Acute renal failure - definition, outcome measures, animal models, fluid therapy and information technology needs: the Second International Consensus Conference of the Acute Dialysis Quality Initiative (ADQI) Group. Crit Care 8: R204-R212.

2. Chertow GM, Burdick E, Honour M, Bonventre JV, Bates DW (2005) Acute kidney injury, Mortality, Length of Stay, and Costs in Hospitalized patients. J Am Soc Nephrol 16: 3365-3370.

3. Chertow GM, Levy EM, Hammermeister KE, Grover F, Daley J (1998) Independent association between acute renal failure and mortality following cardiac surgery. Am J Med 104: 343-348.

4. Nash K, Hafeez A, Hou S (2002) Hospital-acquired renal insufficiency. Am J Kidney Dis 39: 930-936.

5. Hsu CY, McCulloch CE, Fan D, Ordonez JD, Chertow GM, et al. (2007) Community-based incidence of acute renal failure. Kidney Int 72: 208-212.

6. Mehta RL, Kellum JA, Shah SV, Molitoris BA, Ronco C, et al. (2007) Acute Kidney Injury Network. Acute Kidney Injury Network: report of an initiative to improve outcomes in acute kidney injury. Crit Care 11: R31.

7. Siew ED, Peterson JF, Eden SK, Moons KG, Ikizler TA, et al. (2013) Use of multiple imputation method to improve estimation of missing baseline serum creatinine in acute kidney injury reseacrh. Clin J Am Soc Nephrol 8: 10-18.

8. Siew ED, Matheny ME, Ikizler TA, Lewis JB, Miller RA, et al. (2010) Commonly used surrogates for baseline renal function affect the classification and prognosis of acute kidney injury. Kidney Int 77: 536-542.

9. N Newsome BB, Warnock DG, McClellan WM, Herzog CA Kiefe Cl, et al. (2008) Long-term risk of mortality and end-stage renal disease among the elderly after small increases in serum creatinine level during hospitalization for acute myocardial infarction. Arch Intern Med 168: 609-616.

10. Chao CT, Wu VC, Lai CF, Shiao CC, Huang TM, et al. (2012) Advanced age affects the outcome-predictive power of RIFLE classification in geriatric patients with acute kidney injury. Kidney Int 82: 920-927.

*Corresponding author: Chia Ter Chao, M.D, Department of Internal Medicine National Taiwan University Hospital, 7 Chung-Shan South Road, Zhong-Zheng District, Taipei 100, Taiwan, Tel: +886 223123456 ext. 63098; Fax: +886 2 23952333; E-mail: b88401084@gmail.com.

Received January 02, 2013; Accepted January 05, 2013; Published January 25 2013

Citation: Chao CT (2013) Diagnosis of Acute Kidney Injury: Current Controversies Gen Med (Los Angel) 1: e101. doi: 10.4172/2327-5146.1000e101

Copyright: (๑) 2013 Chao CT. This is an open-access article distributed under the terms of the Creative Commons Attribution License, which permits unrestricted use, distribution, and reproduction in any medium, provided the original author and source are credited. 
Citation: Chao CT (2013) Diagnosis of Acute Kidney Injury: Current Controversies. Gen Med (Los Angel) 1: e101. doi: 10.4172/2327-5146.1000e101

Page 2 of 2

11. Waikar SS, Bonventre JV (2009) Creatinine kinetics and the definition of acute kidney injury. J Am Soc Nephrol 20: 672-679.
12. Siew ED, Ware LB, Ikizler TA (2011) Biological markers of acute kidney injury. J Am Soc Nephrol 22: 810-820. 